\title{
Too little, too slowly: international perspectives on childhood obesity
}

\author{
Adrian Baumana,d, Harry Rutterb and Louise Baur ${ }^{\mathrm{c}}$ \\ a Prevention Research Collaboration, Sydney School of Public Health, University of Sydney, NSW, Australia \\ b Department of Social \& Policy Sciences, University of Bath, UK \\ c Discipline of Child and Adolescent Health, Sydney Medical School, University of Sydney, NSW, Australia \\ ${ }^{d}$ Corresponding author: adrian.bauman@sydney.edu.au
}

\section{Article history}

Publication date: March 2019

Citation: Bauman A, Rutter H, Baur L.

Too little, too slowly: international perspectives on childhood obesity. Public Health Res Pract. 2019;29(1):e2911901. https://doi.org/10.17061/phrp2911901

\section{Key points}

- Rates of overweight and obesity in childhood and adolescence have increased over recent decades, with a recent plateau seen in some high-income countries

- Childhood obesity surveillance systems are patchy, often rely on self-report data and rarely assess environmental or broader determinants

- The World Health Organization's Commission on Ending Childhood Obesity provides a current distillation of evidence based approaches, but these are infrequently implemented

- Although there have been policy responses designed to address factors in childhood obesity in some countries, political action lags well behind what is needed

\section{Abstract}

Childhood obesity is a global concern. The prevalence of childhood overweight and obesity is increasing in many countries at all levels of development, for school-aged children and adolescents aged 5-19 years as well as preschool children younger than 5 years. Childhood obesity has implications not only for children's physical and psychological health, but it increases the risk of obesity and noncommunicable diseases into adulthood. The World Health Organization's Commission on Ending Childhood Obesity has called for governments to recognise their "moral responsibility" to act to reduce the risk; however, political action lags well behind what is needed. In this article, we examine global trends, surveillance systems and international examples of policy and progress, and describe the challenges for preventing childhood obesity.

\section{Global trends}

Over the past four decades, increases in childhood obesity have been noted in school-aged populations using pooled data from 31.5 million children and adolescents aged 5-19 years. ${ }^{1}$ The global proportion of children with obesity has increased from 0.7 and $0.9 \%$ (for girls and boys, respectively) in 1975 to 5.6 and $7.8 \%$ in $2016 .^{1}$ These rates have started to plateau in some highincome countries, while increases have continued in middle-income countries and, in particular, countries such as Pacific Island nations. Some show a 'delayed start' pattern, including high-income countries such as Japan and the Netherlands which, even by the year 2000, had half the childhood obesity rate of the UK and a quarter that of the US. The global number of infants and children aged younger than 5 years with overweight or obesity has increased from 32 million in 1990 to more than 41 million in 2016, with increases again more notable in middle-income countries. ${ }^{2}$

Although many types of change have been described ${ }^{3}$, three obvious patterns are clear and take account of most countries, albeit with different baselines in the 1970s and endpoint prevalences of childhood obesity in 2016. These are shown schematically in Figure 1 and reflect: 1) consistent early increases with an apparent plateau effect (e.g. UK, Australia and Denmark); 2) low levels with recent exponential increases (e.g. Gulf States, 
several Latin American countries); and 3) consistent linear increases across the whole period (e.g. Pacific Island nations). Even where overall plateau effects are reported, prevalence in disadvantaged subpopulations may continue to increase. Similar patterns are reported for early childhood (ages 0-5 years).

Figure 1. Three major patterns of obesity prevalence trends

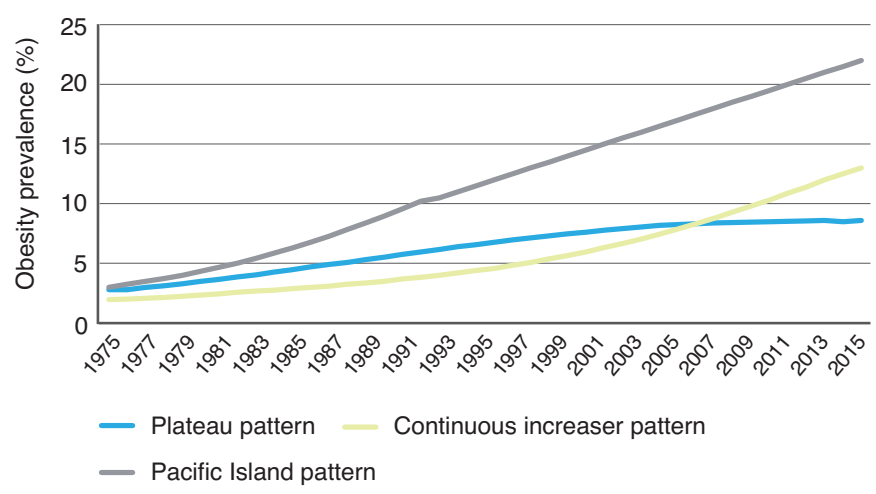

Note: Adapted from NCD-RisC (NCD Risk Factor Collaboration) online $^{3}$

The development of childhood obesity shows a mixed relation to socio-economic status. In middle-income countries, the increases in childhood obesity are initially most rapid in economically advantaged subgroups, such as is seen in China. ${ }^{4}$ In high-income countries, a reverse pattern exists, with disadvantaged children showing higher childhood obesity rates (e.g. Sweden, Czech Republic), although more complex mixed patterns are also seen in some European and Asian countries. . $^{5}$ Widening of socio-economic-associated inequalities in childhood obesity rates has been reported in high-income countries, as well articulated in a study of four population cohorts in the UK over five decades. ${ }^{7}$

\section{Surveillance systems}

Effective responses to obesity require robust data. Population childhood obesity surveillance data are collected through the European quadrennial Health Behaviour in School-aged Children surveys ${ }^{8}$, youth surveys in the US' ${ }^{9}$, and low- to middle-income country data from the WHO Global School-based Student Health Survey. ${ }^{10}$ However, these data are self-reported, which may misclassify adolescents with overweight/obesity.

WHO Europe coordinates the Child Obesity Surveillance Initiative, which collects measured height and weight from more than 250000 children aged between 6 and 9 years, providing nationally representative samples across 40 countries in Europe. ${ }^{11}$ Within country, the English National Child Measurement Programme has measured obesity objectively since 2006, providing robust data on trends by sex, deprivation and ethnicity. ${ }^{12}$ These data are collected during children's first and last year of primary school, providing representative, comprehensive data on more than 1 million children each year. Such surveillance data are a substantial improvement on self-reported or parent-reported information.

Surveillance should also document policy development and program implementation and reach. One such example is the WHO country capacity surveys, which monitor the existence of national strategies to reduce unhealthy food marketing to children. In the 2017 survey, one-third of European countries reported government-legislated strategies, but very few were reported by Asian or African countries. ${ }^{13}$

\section{Commission on Ending Childhood Obesity (ECHO)}

WHO established $\mathrm{ECHO}$ in response to increases in childhood obesity in low- and middle-income countries. The commission's final report ${ }^{14}$ called for governments "to take leadership and for all stakeholders to recognise their moral responsibility in acting on behalf of the child to reduce the risk of obesity". The report outlined six key areas of action (Figure 2).

Although many of the detailed recommendations focus on the child and family, they also cover broader upstream issues including implementing an effective tax on sugarsweetened beverages and implementing recommendations on the marketing of foods. The ECHO implementation plan was presented to the World Health Assembly in May 2017, where there was a noticeably cautious response, whereby "delegates welcomed a plan to implement recommendations", rather than endorsing or adopting the report. ${ }^{15}$ Even this WHO ECHO process emphasised individual-level information and education strategies more than recommendations relating to private-sector actions, despite the strong evidence base for the latter. ${ }^{16}$

\section{Political responses}

Lack of success in childhood obesity prevention is often underpinned by the erroneous conceptualisation of the problem as a failure of the individual rather than as a normal response to an 'obesogenic' environment in which people must make an increasing effort to eat small portions of healthy foods, and to engage in daily physical activity. ${ }^{17}$ This focus on individual responsibility drives obesity policy actions that are skewed towards individual-level responses and are unlikely to result in sustained changes in behaviour that lead to long-term alterations in energy balance across the population. There is insufficient focus on the commercial determinants of obesity ${ }^{18}$, namely the need for food and beverage corporations and other stakeholders to change their approaches that currently drive the "obesogenic system". 
Figure 2. WHO Commission on Ending Childhood Obesity report: key areas of action

\begin{tabular}{|c|c|c|c|c|c|}
\hline \multirow{3}{*}{$\begin{array}{l}\text { Preconception } \\
\text { weight and good } \\
\text { antenatal care } \\
\text { Prevent excess } \\
\text { weight gain } \\
\text { in pregnancy, } \\
\text { monitor weight }\end{array}$} & & \multirow{3}{*}{$\begin{array}{l}\text { Infancy } \\
\text { Encourage } \\
\text { breastfeeding; } \\
\text { regulate } \\
\text { complementary } \\
\text { foods }\end{array}$} & \multirow{3}{*}{$\begin{array}{l}\text { Early child hood } \\
\text { Encourage healthy } \\
\text { eating; encourage } \\
\text { active play } \\
\text { (physical activity) } \\
\text { at home and in } \\
\text { preschool }\end{array}$} & \multirow{3}{*}{$\vec{\longrightarrow}$} & $\begin{array}{c}\text { Equitable health services - weight management } \\
\text { programs and treatment; increase access for } \\
\text { overweight/obese children }\end{array}$ \\
\hline & & & & & $\begin{array}{c}\text { Best practice in promoting healthy foods at home } \\
\text { and school; regulate food marketing; sugar- } \\
\text { sweetened beverage taxation }\end{array}$ \\
\hline & & & & & $\begin{array}{l}\text { Physical activity promoted; mandatory school } \\
\text { physical education; active commuting to school } \\
\text { encouraged with environmental supports }\end{array}$ \\
\hline & Birth & & ly childhood & & Primary school \\
\hline
\end{tabular}

Source: Adapted from WHO Report of the Commission on Ending Childhood Obesity ${ }^{14}$

There has, however, been a policy shift in some innovative jurisdictions in recent years with the introduction of fiscal measures to reduce sugarsweetened beverage consumption, a discrete risk factor for childhood obesity. These 'sugar taxes' have been introduced in a growing number of countries, most recently the UK. Initial evaluations show important changes in consumer behaviour in Mexico and Berkeley (US). ${ }^{19,20}$ The UK sugar-sweetened beverages tax, which sits at two different tiers, also appears to have driven a large amount of reformulation by producers, to reduce the sugar content of drinks below the taxable threshold. ${ }^{21}$

There are also examples of effective actions at regional and local levels. When he was Mayor of New York City, Michael Bloomberg led city-wide cross-agency initiatives to develop sustainable policies that promoted healthier eating and increased physical activity - which was accompanied by reductions in childhood obesity. ${ }^{22}$ The Amsterdam Healthy Weight Program, another citylevel intersectoral program, appears to have had an impact on reducing population-group inequalities in obesity. ${ }^{23}$ This intervention involves collaboration across multiple agencies including supermarkets and food vendors, influencing the school environment, promoting sport and active commuting to school, and providing screening and clinical services for children with obesity. ${ }^{20}$ Further examination of these interventions and their mechanisms of effect is warranted.

\section{Social marketing and mass media campaigns}

There is widespread interest in mass communications strategies in childhood obesity prevention. Ideally, media campaigns should be sustained to inform consumers, and to increase community support, in turn influencing decision makers with respect to legislation relating to childhood obesity. ${ }^{24}$ Other campaigns can influence parental understanding of the role of sugar-sweetened beverages in childhood obesity ${ }^{25}$, as well as other issues such as food labelling and portion size. Social media, and marketing and advertising of unhealthy foods, may target children. ${ }^{26}$ Many countries have voluntary codes or standards for food advertising, but self-regulation is seldom adhered to by the food industry, and governments rarely impose mandatory regulations. Finally, in order to prevent stigmatising overweight children, careful testing and framing of obesity messages is important. ${ }^{27}$

\section{Health services}

Although the primary prevention of childhood obesity is vital, so too is effective management of children already affected. One ECHO recommendation is for "weight management services ... that are family based, multicomponent (including nutrition, physical activity and psychosocial support) and delivered by multiprofessional teams ... as part of Universal Health Coverage". ${ }^{15}$ However, in many countries, including Australia, those affected by obesity often lack access to treatment, existing services are patchy and inequitably distributed, and health professionals receive limited training in childhood assessment and management. These issues are compounded by resource constraints and often also a pervasive institutional weight stigma. There remains a pressing need for cost-effective implementation of health system models of service provision and health professional training. The World Obesity Federation has recently recognised this issue through its Health Systems Committee, which is identifying best practice examples from different countries. 


\section{Conclusions}

Recent trends in the prevalence of childhood obesity, notwithstanding plateauing in some countries, indicate a huge burden of current and future ill health. The global need for robust and intensive action remains, but despite significant efforts in many countries, the policy response lags behind what is needed. This is despite the fact that the WHO ECHO Commission report recommended strong political leadership to ensure implementation of these and other responses. Urgent, coordinated health system responses are needed to manage the many children already affected by obesity. Finally, standardised population surveillance systems, using objective assessments of obesity, and integrated with policy monitoring, are required to track sustained progress in program implementation and obesity outcomes.

\section{Peer review and provenance}

Externally peer reviewed, commissioned.

\section{Competing interests}

None declared.

\section{Author contributions}

All authors designed this article. AB drafted the paper, HR and LB made detailed comments and edits, and all authors were involved in the final submission and revision of the paper.

\section{References}

1. Abarca-Gómez L, Abdeen ZA, Hamid ZA, AbuRmeileh NM, Acosta-Cazares B, Acuin C, et al. Worldwide trends in body-mass index, underweight, overweight, and obesity from 1975 to 2016: a pooled analysis of 2416 population-based measurement studies in 128.9 million children, adolescents, and adults. Lancet. 2017;390(10113):2627-42.

2. De Onis M, Blössner M, Borghi E. Global prevalence and trends of overweight and obesity among preschool children. Am J Clin Nutr. 2010;92(5):1257-64.

3. NCD-RisC: Risk Factor Collaboration. London: NCD Risk Factor Collaboration; 2017 [cited 2018 Apr]. Available from: ncdrisc.org/

4. Jia P, Xue H, Zhang J, Wang Y. Time trend and demographic and geographic disparities in childhood obesity prevalence in China - evidence from twenty years of longitudinal data. Int J Environ Res Public Health. 2017;14(4):E369
5. Lissner L, Wijnhoven TMA, Mehlig K, Sjöberg A, Kunesova M, Yngve A, et al. Socioeconomic inequalities in childhood overweight: heterogeneity across five countries in the WHO European Childhood Obesity Surveillance Initiative (COSI-2008). Int J Obes. 2016;40(5):796-802

6. Bahk J, Khang YH. Trends in measures of childhood obesity in Korea from 1998 to 2012. J Epidemiol. 2016;26(4):199-207.

7. Bann D, Johnson WO, Li L, Kuh D, Hardy R. Socioeconomic inequalities in body mass index, weight, and height in childhood and adolescence: coordinated analyses of individual participant data from four British birth cohort studies initiated in 1946, 1958, 1970, and 2001. Lancet Public Health. 2018:3(4):e194-e203.

8. HBSC: Health Behaviour in School-aged Children - World Health Organization Collaborative Cross-National Survey. St Andrews, UK: HBSC. HBSC member countries [cited 2018 Jan 31]. Available from: www.hbsc.org/membership/ countries/index.html

9. Centers for Disease Control and Prevention. Youth risk behaviour survey results and trends report. Atlanta, GA: Centers for Disease Control and Prevention; 2018 [cited 2019 Jan 28]. Available from: www.cdc.gov/features/yrbs/ index.html

10. World Health Organization. Geneva: WHO; 2019. Global school-based student health survey (GSHS); 2017 [cited 2019 Jan 28]. Available from: www.who.int/ncds/ surveillance/gshs/en/

11. World Health Organization. Geneva: WHO; 2019. WHO European childhood obesity surveillance initiative (COSI); [cited 2018 Dec]. Available from: www.euro.who.int/en/ health-topics/disease-prevention/nutrition/activities/whoeuropean-childhood-obesity-surveillance-initiative-cosi

12. NHS Digital. Leeds, UK: NHS Digital. National child measurement programme; [cited 2018 Jan 31], Available from: digital.nhs.uk/areas-of-interest/public-health/ national-child-measurement-programme

13. World Health Organization. Geneva: WHO; 2018. Assessing national capacity for the prevention and control of NCDs [cited 2019 Jan 12]; [about 2 screens]. Available from: www.who.int/ncds/surveillance/ncdcapacity/en/

14. World Health Organization. Report of the Commission on Ending Childhood Obesity. Geneva: WHO; 2016 [cited 2019 Jan 28]. Available from: www.who.int/endchildhood-obesity/final-report/en/

15. World Health Organization. Report of the Commission on Ending Childhood Obesity: implementation plan. Geneva: WHO; 2017 [cited 2019 Jan 29] Available from: apps. who.int/iris/bitstream/handle/10665/259349/WHO-NMHPND-ECHO-17.1-eng. pdf?sequence=1 
16. Swinburn BA, Sacks G, Hall KD, McPherson K, Finegood DT, Moodie ML, Gortmaker SL. The global obesity pandemic: shaped by global drivers and local envinments. Lancet. 2011;378(9793):804-14.

17. Rodgers A, Woodward A, Swinburn B, Dietz WH. Prevalence trends tell us what did not precipitate the US obesity epidemic. Lancet Public Health. 2018;3(4):e162-3.

18. Kickbusch I, Allen L, Franz C. The commercial determinants of health. Lancet Global Health. 2016;4(12):e895-6.

19. Colchero MA, Popkin BM, Rivera JA, Ng SW. Beverage purchases from stores in Mexico under the excise tax on sugar sweetened beverages: observational study. BMJ. 2016;352:h6704.

20. Silver LD, Ng SW, Ryan-Ibarra S, Taillie LS, Induni M, Miles DR, et al. Changes in prices, sales, consumer spending, and beverage consumption one year after a tax on sugar-sweetened beverages in Berkeley, California, US: a before-and-after study. PLoS Medicine. 2017;14(4):e1002283.

21. GOV.UK. London: Crown. News story: soft drinks industry levy comes into effect; 2018 Apr 5 [cited 2019 Jan 31]; [about 3 screens]. Available from: www.gov.uk/ government/news/soft-drinks-industry-levy-comes-intoeffect

22. Kelly PM, Davies A, Greig AJ, Lee KK. Obesity prevention in a city state: lessons from New York City during the Bloomberg administration. Front Public Health. 2016;4:60.
23. Hawkes C, Russell S, Isaacs A, Rutter H, Viner $\mathrm{H}$. What can be learned from the Amsterdam Healthy Weight programme to inform the policy response to obesity in England? Rapid response briefing paper. London: Obesity Policy Research Unit; 2017 [cited 2019 Jan 28]. Available from: www.ucl.ac.uk/obesity-policy-researchunit/sites/obesity-policy-research-unit/files/what-learnedfrom-amsterdam-healthy-weight-programme-informpolicy-response-obesity-england.pdf

24. Bleich SN, Jones-Smith J, Jones H, O'Hara M, Rutkow L. The voices for Healthy Kids campaign and US state legislation to prevent childhood obesity. Am J Public Health. 2016;106(3):436-9.

25. Boles M, Adams A, Gredler A, Manhas S. Ability of a mass media campaign to influence knowledge, attitudes, and behaviors about sugary drinks and obesity. Prev Med. 2014;67(S1):S40-5.

26. Mazur A, Caroli M, Radziewicz-Winnicki I, Nowicka P, Weghuber D, Neubauer D, et al. Reviewing and addressing the link between mass media and the increase in obesity among European children: the European Academy of Paediatrics (EAP) and the European Childhood Obesity Group (ECOG) consensus statement. Acta Paediatr. 2018;107(4):568-76.

27. Young R, Subramanian R, Hinnant A. Stigmatizing images in obesity health campaign messages and healthy behavioral intentions. Health Educ Behav. 2016;43(4):412-9.

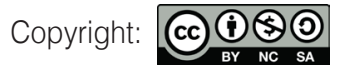

(C) 2019 Bauman et al. This article is licensed under the Creative Commons Attribution-NonCommercial-ShareAlike 4.0 International Licence, which allows others to redistribute, adapt and share this work non-commercially provided they attribute the work and any adapted version of it is distributed under the same Creative Commons licence terms. See: www.creativecommons.org/licenses/by-nc-sa/4.0/ 